\title{
Stock specific high-seas distribution of maturing sockeye salmon in the North Pacific
}

\author{
Boris Espinasse $^{1}$, Brian Hunt ${ }^{1}$, Bruce Finney ${ }^{2}$, Jeffrey Fryer ${ }^{3}$, Alexander Rubaev ${ }^{4}$, and \\ Evgeny Pakhomov ${ }^{1}$ \\ ${ }^{1} \mathrm{UBC}$ \\ ${ }^{2}$ Idaho State University \\ ${ }^{3}$ Columbia River Inter-Tribal Fish Commission \\ ${ }^{4}$ Kamchatka Research Institute of Fisheries and Oceanography
}

May 5, 2020

\begin{abstract}
The stock-specific distribution of maturing and adult salmon in the Northeast (NE) Pacific has been a persistent information gap that has prevented us from determining the ocean conditions experienced by individual stocks. This continues to impede understanding of the role of ocean conditions in stock-specific population dynamics. We assessed scale archives for 17 sockeye salmon (Oncorhynchus nerka) stocks covering the entire North Pacific, from the Columbia River to Kamchatka Peninsula, to define salmon locations during their last growing season before returning to their spawning grounds. We used the relationship between $\delta 13 \mathrm{C}$ in salmon scales and sea water temperature to estimate salmon distribution based on correlation strength. Significant correlations were found for 13 of the stocks allowing us to define feeding grounds with confidence. Complementary information from $\delta 15 \mathrm{~N}$, historical tagging studies, and connectivity analysis were used to further refine distribution estimates. Based on the estimated distributions of the NE Pacific stocks, we suggest a sequence of steps that could result in salmon marine distributions. This study is a first step toward determining stock-specific distributions of salmon in the NE Pacific, and provides a basis for the application of the approach to other salmon scale archives. This information will improve our ability to relate stock dynamics to ocean conditions, ultimately enabling improved stock management. For example, our estimated distributions of Bristol Bay and NE Pacific stocks demonstrated that they occupy different areas with a number of the former being distributed in the high productivity shelf waters of the Aleutian Islands and Bering Sea. This may explain while these stocks seem to have responded differently to changes in ocean conditions, and the long term trend of increased productivity of Bristol Bay sockeye.
\end{abstract}

\section{Introduction}

Sockeye salmon (Oncorhynchus nerka) migrate from freshwater to the coastal ocean as juveniles and rapidly migrate from the coast to the open ocean where they typically reside for 2 to 3 years before returning to their natal streams to spawn (Burgner, 1991). Although it is considered that the early marine life phase is the period most critical to survival, there are indications that much of the cumulative juvenile-to-adult mortality of salmon occurs on the high seas (McKinnell, Curchitser, Groot, Kaeriyama, \& Trudel, 2014; Welch et al., 2011). It is also during this period, and especially during maturation, that the fish accumulate most of their mass (Ishida, Soto-o, Ueno, \& Sakai, 1998) and establish the body condition necessary to undertake successful spawning migration and reproduction. However, our understanding of the high seas life phase and its role on determining stock specific recruitment dynamics remains limited. This knowledge gap reflects the challenges posed by the massive spatial scale of the North Pacific, the wide dispersal of fish, and the associated expense and logistical challenges of sampling. 
Many sockeye salmon spawning grounds are located at considerable distance from the sea (up to 100's $\mathrm{km}$ ), requiring substantial reserves for upstream migration. The energy requirements depend on water temperature, that will affect salmon metabolic rate, distance, and river flow strength, both of which determine the relative migration duration (Crossin et al., 2008; J. Stevenson Macdonald, Patterson, Hague, \& Guthrie, 2010; Rand et al., 2006). It has previously been demonstrated that high adult returns and high productivity (adult recruits produced per spawner) are not necessarily linked. In 1997, Fraser River sockeye returned to the river with poor body condition (smaller size, low lipid content) and concurrently experienced extremely high river discharge (60 to $100 \%$ greater than mean levels), resulting in the largest en-route mortality recorded for the Fraser system (Macdonald, 2000). The poor fish condition when entering the freshwater system that year has been suggested to be have been due to warmer sea surface temperature (SST), associated with a record setting El Niño event, and density-dependent effects (S. M. McKinnell, 2000). Warmer than usual temperatures experienced by the fish in the high seas were suggested to have resulted in altered salmon phenology (early maturating) and reduced nutritional health (low lipid content).

Another direct effect of a warming North Pacific Ocean on salmon is a reduction in the area of suitable thermal habitat (Abdul-Aziz, Mantua, \& Myers, 2011; Healey, 2011; Welch, Ishida, \& Nagasawa, 1998). This is expected to result in an intensification of competition for resources. Recent studies indicate that competition for food among salmon species in the open ocean can play a role in regulating populations (Ruggerone \& Connors, 2015; Springer \& van Vliet, 2014). Increasing pink salmon abundance (Oncorhynchus gorbuscha), in part due to hatchery enhancement, combined with the limited carrying capacity of the North Pacific Ocean could result in unfavorable conditions for sockeye development. However, the influence of food composition and abundance on salmon development and condition remains largely unknown, although Pacific salmon seem to be able to adapt their diet when food conditions change (Kaeriyama et al., 2004).

A prerequisite to determining the extent to which these different processes affect sockeye salmon stocks is knowledge of salmon distributions in the high seas (Chittenden, Beamish, \& McKinley, 2009). However, this is an extremely challenging task due to the enormous technical and logistical difficulty associated with tracking and monitoring salmon populations at the scale of ocean basins. As a consequence, salmon distributions in the ocean have been only coarsely defined to date and are almost completely unknown when it comes to specific stocks, with the exception of intensive tagging studies carried out by fishery vessels in the 50-60's (French, Bilton, Osako, \& Hartt, 1976). In the future, at-sea genomic analysis may help to resolve this knowledge gap, however, biogeochemical approaches may provide a means to retrospective resolve estimate ocean distributions. The Carbon $\left(\delta^{13} \mathrm{C}\right)$ and Nitrogen $\left(\delta^{13} \mathrm{~N}\right)$ stable isotope ratios of salmon scales provide a useful tool to estimate the environmental conditions experienced by fish and their distribution (MacKenzie et al., 2012; Torniainen et al., 2014; Trueman, MacKenzie, \& Palmer, 2012). In particular, covariance of SST and $\delta^{13} \mathrm{C}$ provide a reliable indicator to track animal location (MacKenzie et al., 2011; McMahon, Hamady, \& Thorrold, 2013). This relationship is based on the water temperature control of aqueous $\left[\mathrm{CO}_{2}\right]$, which in turns controls carbon isotope fractionation by autotrophs. Because autotrophs preferentially take up the lighter carbon isotope $\left({ }^{12} \mathrm{C}\right.$ ), high $\left[\mathrm{CO}_{2}\right]$ concentration (low SST) result in low $\delta^{13} \mathrm{C}$, and conversely a decrease in concentrations (high SST) lead to higher $\delta^{13} \mathrm{C}$ as autotrophs have reduced access to the light isotope (Goericke \& Fry, 1994; Rau, Takahashi, \& Marais, 1989). Although other mechanisms linked to phytoplankton physiology and community composition do affect phytoplankton $\delta^{13} \mathrm{C}$ values (Burkhardt, Riebesell, \& Zondervan, 1999; Riebesell, Burkhardt, Dauelsberg, \& Kroon, 2000), water temperature is considered to be the main driver of $\delta^{13} \mathrm{C}$ variation at high latitude (Magozzi, Yool, Zanden, Wunder, \& Trueman, 2017). Recently, the $\delta^{13} \mathrm{C} /$ SST correlation has been used to identify salmon feeding grounds in the North Atlantic (MacKenzie et al., 2011) and for one sockeye stock in the North Pacific (Espinasse, Hunt, Doson Coll, \& Pakhomov, 2018).

In this study, we build on the preliminary work of Espinasse et al. (2018) to assess stock specific sockeye salmon distributions in the North Pacific through analysis of archived scales for 17 North Pacific sockeye salmon stocks. These scales were all collected in or near the freshwater system and differed in the time range covered, sampling resolution (yearly, every $3^{\text {rd }}$ year, irregular), and material type (whole scale or last annulus). Our primary objectives were to determine whether salmon feeding grounds can accurately 
be described based on the $\delta^{13} \mathrm{C} / \mathrm{SST}$ relationship and the robustness of this method. We discuss the implications of our results for our understanding of salmon high seas migration history.

\section{Materials and Methods}

Data collection and scale processing

The literature was reviewed for published SI data of sockeye salmon scales. Johnson and Schindler (2012) reported on SI data for eight stocks distributed in Bristol Bay with time series spanning over four decades of scales collected every three years. Satterfield and Finney (2002) reported on a 30-year time series with yearly resolution for a stock located on Kodiak Island in SW Alaska, and Espinasse et al. (2018) reported on SI data for the Rivers Inlet stock (BC coast) which covered more than 50 years with irregular sampling resolution. In addition, we accessed archived scales for two major stocks in the Kamchatka Peninsula (Ozernaya and Kamchatka) (Bugaev et al., 2008), for two stocks of the Columbia River (Okanagan and Wenatchee), for two stocks in SE Alaska (Chilkoot and Chilkat) and for one additional stock on Kodiak Island. The stock locations can be seen in Figure 1 and the details of the time series resolution are provided in Table 1.

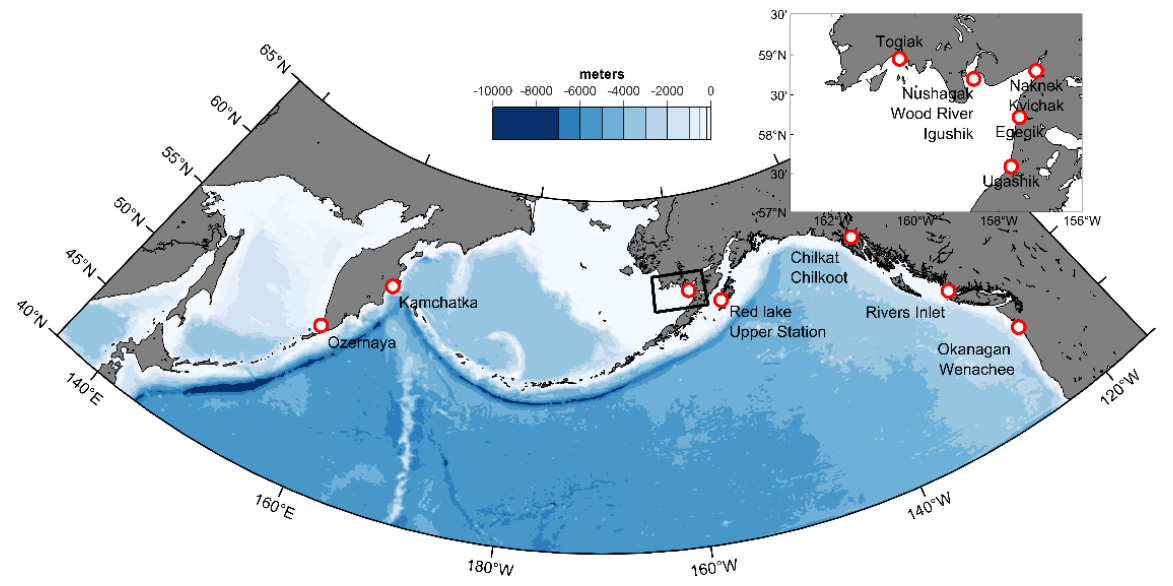

Figure 1. Map of the study area with locations of the sockeye salmon stocks investigated.

\begin{tabular}{|c|c|c|c|c|c|}
\hline Salmon stock & Time range & $\begin{array}{l}\text { Sampling } \\
\text { frequency }(\# \\
\left.\text { sample } \mathrm{yr}^{-1}\right) / \\
\text { Nbr. data point }\end{array}$ & $\delta^{13} \mathrm{C}$ range ( & $\delta^{15} \mathrm{~N}$ range ( & $\delta^{13} \mathrm{C}$ vs $\delta^{15} \mathrm{~N}$ \\
\hline Kodiak Island & 1967-1999 & $\begin{array}{l}\text { every year } \\
(2-5), \text { last } \\
\text { annulus only }\end{array}$ & & & \\
\hline Red Lake ${ }^{1}$ & & $n=32$ & $-19.05--17.17$ & $8.29-11.62$ & 0.22 \\
\hline Upper station & & $n=31$ & $-18.88--17.38$ & $8.08-10.68$ & $0.57 * * *$ \\
\hline SE Alaska & 1968-1998 & $\begin{array}{l}\text { every year } \\
(2-5), \text { last } \\
\text { annulus only }\end{array}$ & & & \\
\hline Chilkoot & & $n=29$ & $-18.92--17.43$ & $9.46-11.66$ & $0.67^{* * *}$ \\
\hline Chilkat & & $n=29$ & $-19.29--17.18$ & $8.43-10.64$ & 0.12 \\
\hline Columbia & 1986-2016 & every year (5) & & & \\
\hline Okanagan & & $n=31$ & $-18.97--17.82$ & $9.68-10.96$ & $0.52^{* *}$ \\
\hline Wenachee & & $n=31$ & $-18.97--17.50$ & $9.68-11.32$ & $0.57 * * *$ \\
\hline $\mathrm{BC}$ coast & $1960-2016$ & $\begin{array}{c}\text { irregular } \\
(18-135)\end{array}$ & & & \\
\hline
\end{tabular}




\begin{tabular}{|c|c|c|c|c|c|}
\hline Salmon stock & Time range & $\begin{array}{l}\text { Sampling } \\
\text { frequency (\# } \\
\left.\text { sample yr }{ }^{-1}\right) / \\
\text { Nbr. data point }\end{array}$ & $\delta^{13} \mathrm{C}$ range ( & $\delta^{15} \mathrm{~N}$ range ( & $\delta^{13} \mathrm{C}$ vs $\delta^{15} \mathrm{~N}$ \\
\hline Rivers Inlet $^{2}$ & & $n=16$ & $-18.26--16.98$ & $9.57-11.11$ & 0.02 \\
\hline S Bristol Bay ${ }^{3}$ & $1962-2003$ & $\begin{array}{l}\text { every } 3^{\text {rd }} \text { year } \\
(3-5)\end{array}$ & & & \\
\hline Ugashik & & $n=14$ & $-18.13--16.98$ & $10.47-12.03$ & 0.37 \\
\hline Egegik & & $n=15$ & $-18.21--16.75$ & $10.50-11.68$ & 0.29 \\
\hline Naknek & & $n=13$ & $-18.04--16.79$ & $10.48-12.22$ & $0.69^{* *}$ \\
\hline Kvichak & & $n=11$ & $-18.14--17.32$ & $10.99-11.88$ & 0.07 \\
\hline N Bristol Bay ${ }^{3}$ & $1962-2003$ & $\begin{array}{l}\text { every } 3^{\text {rd }} \text { year } \\
(3-5)\end{array}$ & & & \\
\hline Nushagak & & $n=14$ & $-17.87--16.80$ & $10.89-12.76$ & 0.06 \\
\hline Wood River & & $n=14$ & $-18.07--17.37$ & $11.35-12.97$ & 0.29 \\
\hline Igushik & & $n=14$ & $-18.44--16.62$ & $10.79-12.14$ & 0.16 \\
\hline Togiak & & $n=15$ & $-18.05--16.88$ & $11.15-12.15$ & $0.57^{*}$ \\
\hline NW Pacific & $1995-2017$ & $\begin{array}{l}\text { every year } \\
(3-5)\end{array}$ & & & \\
\hline Ozernaya & & $n=23$ & $-18.31--17.46$ & $10.59-11.45$ & 0.24 \\
\hline Kamchatka & & $n=11$ & $-18.33--17.39$ & $10.45-11.48$ & -0.01 \\
\hline
\end{tabular}

Table 1. Details of the salmon scale samples analyzed, $\delta^{13} \mathrm{C}$ (corrected for Suess effect) and $\delta^{15} \mathrm{~N}$ ranges and correlation coefficients between these two SI ratios. P-values significance is: ${ }^{* * *} \mathrm{p}<0.001,{ }^{* *} \mathrm{p}<0.01$, ${ }^{*} \mathrm{p}<0.05$.

${ }^{1}$ Satterfield and Finney, 2002, ${ }^{2}$ Espinasse et al. 2018, ${ }^{3}$ Johnson and Schindler 2012

Kamchatka Peninsula salmon were collected at the river mouths, while salmon from Columbia River stocks were collected at Bonneville Dam about $230 \mathrm{~km}$ upstream from the sea. The Okanagan and Wenatchee time series were mixed until 2005 and identified separately afterwards based on tag data. For four of the stocks processed (see Table 1), only the last annulus, which grows over the last year at sea, was processed. The last annulus was excised from the rest of the scale following the description given by Satterfield and Finney (2002). Most of the scales were initially glued on gum cards. All the scales were immerged in water and rubbed thoroughly until the scales were transparent and free of residual glue. Details on SI analysis of scales from SE Alaska and Kodiak Islands can be found in Satterfield and Finney (2002).

The scales processed during this study were dried in an oven for 24 hours at $60^{\circ} \mathrm{C}$ and sent for SI analysis at UC Davis SIF (https://stableisotopefacility.ucdavis.edu/13cand15n.html). The samples were analyzed for ${ }^{13} \mathrm{C}$ and ${ }^{15} \mathrm{~N}$ isotopes using a PDZ Europa ANCA-GSL elemental analyzer interfaced to a PDZ Europa 20-20 isotope ratio mass spectrometer (Sercon Ltd., Cheshire, UK). The system was calibrated using different NIST Standard Reference Materials. Measurement precision was assessed by running replicates of these standards and result in standard deviation consistently below 0.1 both for $\delta^{13} \mathrm{C}$ and $\delta^{15} \mathrm{~N}$. Isotopic ratios are expressed in the following standard notation:

$\delta \mathrm{X}($

where $\mathrm{X}$ is ${ }^{13} \mathrm{C}$ or ${ }^{15} \mathrm{~N}$ and Rsample is the ${ }^{13} \mathrm{C} /{ }^{12} \mathrm{C}$ or ${ }^{15} \mathrm{~N} /{ }^{14} \mathrm{~N}$ respectively. ${ }^{13} \mathrm{C}$ and $\delta^{15} \mathrm{~N}$ were determined in parts per thousand (Belemnite and atmospheric nitrogen, respectively.

The large amount of anthropogenic carbon dioxide released into the atmosphere has led to a long term decrease in both atmospheric and oceanic $\delta^{13} \mathrm{C}$ values, known as the Suess effect (Gruber et al., 1999). The extent of this decrease is directly linked to the rate of change of $\mathrm{CO}_{2}$ concentration and therefore has 
accelerated in recent decades. Analysis of $\delta^{13} \mathrm{C}$ time series should be corrected by adjusting values to a year of reference. We applied a correction factor of -0.02 agreement with recent studies (Espinasse et al., 2018; Williams, Risk, Stone, Sinclair, \& Ghaleb, 2007) and standardized the time series using 2015 as the year of reference.

$\mathrm{C} / \mathrm{N}$ ratios are often used to correct $\delta^{13} \mathrm{C}$ values for the presence of lipids in the materials analyzed (Post et al., 2007). The scales of adult salmon are mainly made out of collagen and as such show constant $\mathrm{C} / \mathrm{N}$ values varying between 2.5 to 2.9. However, for some of the published data (Bristol Bay and Rivers inlet stocks), $\mathrm{C} / \mathrm{N}$ were found out of this range. We suggest that the scales which are not rinsed directly after collection on fish might contain mucus residuals that will stick to the scale even when washed carefully before analysis. We applied a correction for the eight Bristol Bay stocks based on the difference between $\delta^{13} \mathrm{C}$ of scale with $\mathrm{C} / \mathrm{N}>3.5$ and yearly average of $\delta^{13} \mathrm{C}$ scales having a $\mathrm{C} / \mathrm{N}<3.5$. This resulted in correcting values for 65 scales out of 543 with a maximum correction factor of 1.2 correction factor used for Rivers Inlet stock can be found in Boris Espinasse et al. (2018) and is also based on the differences in $\delta^{13} \mathrm{C}$ values between scales with expected $\mathrm{C} / \mathrm{N}$ and scales with relatively high $\mathrm{C} / \mathrm{N}$. It has been questioned if the scales should be acidified prior SI analysis as the external layer of the scale is comprised of mineral apatite that could potentially skew analyses of $\delta^{13} \mathrm{C}$ (Tzadik et al., 2017). However, when the scales grow through the fish life cycle, new layers of collagen are added and the contribution of the external mineral layer to the total weight of the scale decreases (Hutchinson \& Trueman, 2006). Furthermore, Sinnatamby, Bowman, Dempson, and Power (2007) found no significant differences between $\delta^{13} \mathrm{C}$ values of Atlantic salmon scales that were acidified or not. Therefore, none of the scales processed during this study were acidified.

SST data were extracted from the COBE SST2 dataset, which can be downloaded freely at https://www.esrl.noaa.gov/psd/. This dataset provided SST interpolated on a 1 by 1 degree grid, and used a new analysis scheme to reduce uncertainties in analyzed SST (Hirahara, Ishii, \& Fukuda, 2013). SST were averaged for each grid cell from January to June, which generally provides highest correlation coefficients for both whole and excised scales.

\section{Time series processing}

Correlation of time series can be caused by similarity in variations occurring at different frequencies. To be able to identify the relative effect due to long term trends (low frequency) and interannual variability (high frequency), three types of data were used: original data (combination of both effects), detrended data (only interannual variability) and smoothed data (dominance of long term trend). Time series subject to low frequency influence are usually strongly auto-correlated, which violates the assumption of serial independence required for correlation test. One way to account for autocorrelation is to re-assess the number of degrees of freedom, which results in higher p-value for the same correlation coefficient. Pyper and Peterman (1998) developed the so-called 'modified Chelton method' that allows one to calculate a critical correlation coefficient value associated with a given p-value. This method was later adapted by Barker, Hannaford, Chiverton, and Svensson (2016) to account for missing values in time series. We applied this approach for calculation of the p-values for the correlation test of original and smoothed data. Smoothing of the data was conducted using the LOESS method with a span of 0.1-0.2, depending on the time series length, and one degree polynomial. The map plotting was done with the Matlab package M_Map (Pawlowicz, 2019).

\section{Area restriction and result validation}

Initial plotting of the correlation coefficient between $\delta^{13} \mathrm{C}$ and SST can display potential spurious correlations due to inappropriate time series (small dataset or irregular sampling) or synchrony in SST variation across the North Pacific. A range of methods were explored to narrow down the area with highest correlation and propose the most realistic and accurate salmon distributions. The main source of information on salmon distributions in the literature comes from the tagging studies conducted as an international collaboration between Japanese, Canadian and American fishery institutes from 1956 to 1970 (French et al., 1976). More than 60000 sockeye salmon x.2 (two years spent at sea) or older were caught and tagged over this time period. The data were used to produce distribution maps of maturing sockeye, a caveat being that since 
the fish were caught and tagged between late April to June, they were potentially already heading to their natal river system. We digitalized these maps and included them as supplementary materials (Figure S1.1). Another approach to indirectly validate the proposed feeding grounds is to compare the average level of $\delta^{13} \mathrm{C}$ and $\delta^{15} \mathrm{~N}$ values for stocks supposedly distributed in the same area and/or to test for $\delta^{15} \mathrm{~N}$ correlation between stocks (assuming that stocks with the same at-sea distribution will have correlated $\delta^{15} \mathrm{~N}$ series). A pre-requirement for the latter is to check that $\delta^{13} \mathrm{C}$ and $\delta^{15} \mathrm{~N}$ values are not correlated, which is stock dependent. Finally, we used an empirical orthogonal function (EOF) analysis to describe the spatial mode of SST variability. This provided insight into the connectivity between areas with high correlation values.

The mean $\delta^{15} \mathrm{~N}$ of salmon stocks found to be distributed in the NE Pacific were compared with zooplankton SI values published in Espinasse, Hunt, Batten Sonia, and Pakhomov (in press). The zooplankton SI values were extracted from the isoscapes at a location centered on the highest likelihood distribution of each stock and averaged over one degree latitude and longitude. Stock specific trophic level was estimated assuming a trophic enrichment factor of 3.4

\section{Results}

Stock-specific stable isotope values

Large interannual variations were observed for both $\delta^{13} \mathrm{C}$ and $\delta^{15} \mathrm{~N}$ (Figure 2). Stocks that are in close geographic proximity showed similar patterns in SI values variability at low frequency but their SI values can differ substantially over small temporal scale. Suess effect-corrected $\delta^{13} \mathrm{C}$ values showed more stability over time than $\delta^{15} \mathrm{~N}$ and also less variation between stocks with values mainly distributed between -19 to $-17.5 \delta^{15} \mathrm{~N}$ values spanned over 3


Figure 2. Yearly mean of $\delta^{15} \mathrm{~N}$ and $\delta^{13} \mathrm{C}$ values (corrected for Suess effect) in scales of eight sockeye salmon stocks from Kodiak Island (Red Lake and Upper station), SE Alaska (Chillkat and Chilkoot), Columbia River (Okanagan and Wenachee) and Kamchatka Peninsula (Ozernaya and Kamchatka).

For clarity, only unpublished data (with the addition of the Red Lake stock) were represented in the Figure 2 , however the assessment stands for all stocks (Table 1) with the absolute range being wider for $\delta^{15} \mathrm{~N}$ than $\delta^{13} \mathrm{C}$ values, 5.05 vs 2.67 , respectively. Significant correlation between $\delta^{15} \mathrm{~N}$ and $\delta^{13} \mathrm{C}$ appeared random among stocks with no obvious pattern in region or age. A SI biplot of average values shows clear separation 
between the main regions despite the differences in time range covered (Figure 3). Kodiak Island and SE Alaska stocks together with Columbia River stocks showed lower $\delta^{15} \mathrm{~N}$ and $\delta^{13} \mathrm{C}$ values. All Bristol Bay stocks grouped together with higher $\delta^{15} \mathrm{~N}$ values, while Russian stocks and BC coast stocks were positioned between these aforementioned groups.



Figure 3. Biplot of $\delta^{15} \mathrm{~N}$ versus $\delta^{13} \mathrm{C}$ values (corrected for Suess effect) averaged over different time periods (see Table 1) for 17 sockeye salmon stocks. The error bars represent the standard deviation.

\section{Stock-specific feeding grounds}

Table 2. Correlation coefficients between $\delta^{13} \mathrm{C}$ values in salmon scales of several stocks and SST (averaged for Jan-Jun of the year of return). The time series were processed in different ways to disentangle the effect of low and high frequency variability on correlation estimates (original, detrended and smoothed). SST data for each stock were retrieved at the location marked in Figures 4, 5 and 6 by a white cross. P-values were calculated using the modified Chelton method to account for autocorrelation. P-values significance is: $* * *$ $\mathrm{p}<0.001,{ }^{* *} \mathrm{p}<0.01,{ }^{*} \mathrm{p}<0.05$.

\begin{tabular}{llll}
\hline Salmon stock & Correlation coefficient & Correlation coefficient & Correlation coefficient \\
\hline Kodiak Island & Original & Detrended & Smoothed \\
Red Lake & $0.42^{*}$ & 0.25 & - \\
Upper station & $0.44^{* *}$ & $0.42^{*}$ & $0.58^{* *}$ \\
SE Alaska & & & \\
Chilkoot & $0.72^{* *}$ & $0.47^{*}$ & $0.86^{*}$ \\
Chilkat & $0.58^{* * *}$ & $0.57^{* * *}$ & $0.69^{*}$ \\
Columbia & & & \\
Okanagan & $0.59^{* *}$ & $0.55^{* *}$ & $0.73^{* *}$ \\
Wenachee & $0.54^{* *}$ & $0.47^{* *}$ & $0.69^{* *}$ \\
BC coast & & & \\
Rivers Inlet & 0.38 & $0.62^{*}$ & - \\
S Bristol Bay & & & \\
Ugashik & $0.69^{* *}$ & $0.72^{* *}$ & $0.71^{* *}$ \\
Egegik & 0.31 & 0.29 & 0.46. \\
Naknek & $0.68^{*}$ & 0.51 & $0.67^{*}$ \\
Kvichak & $0.61^{*}$ & 0.50 & 0.58. \\
N Bristol Bay & & &
\end{tabular}




\begin{tabular}{llll}
\hline Salmon stock & Correlation coefficient & Correlation coefficient & Correlation coefficient \\
\hline Nushagak & 0.37 & 0.28 & 0.51. \\
Wood River & 0.50. & - & $0.58^{*}$ \\
Igushik & 0.24 & - & 0.31 \\
Togiak & - & - & - \\
NW Pacific & & & \\
Ozernaya & 0.43 & 0.44 & $0.63^{*}$ \\
Kamchatka & 0.41 & 0.43 & 0.60 \\
\hline
\end{tabular}
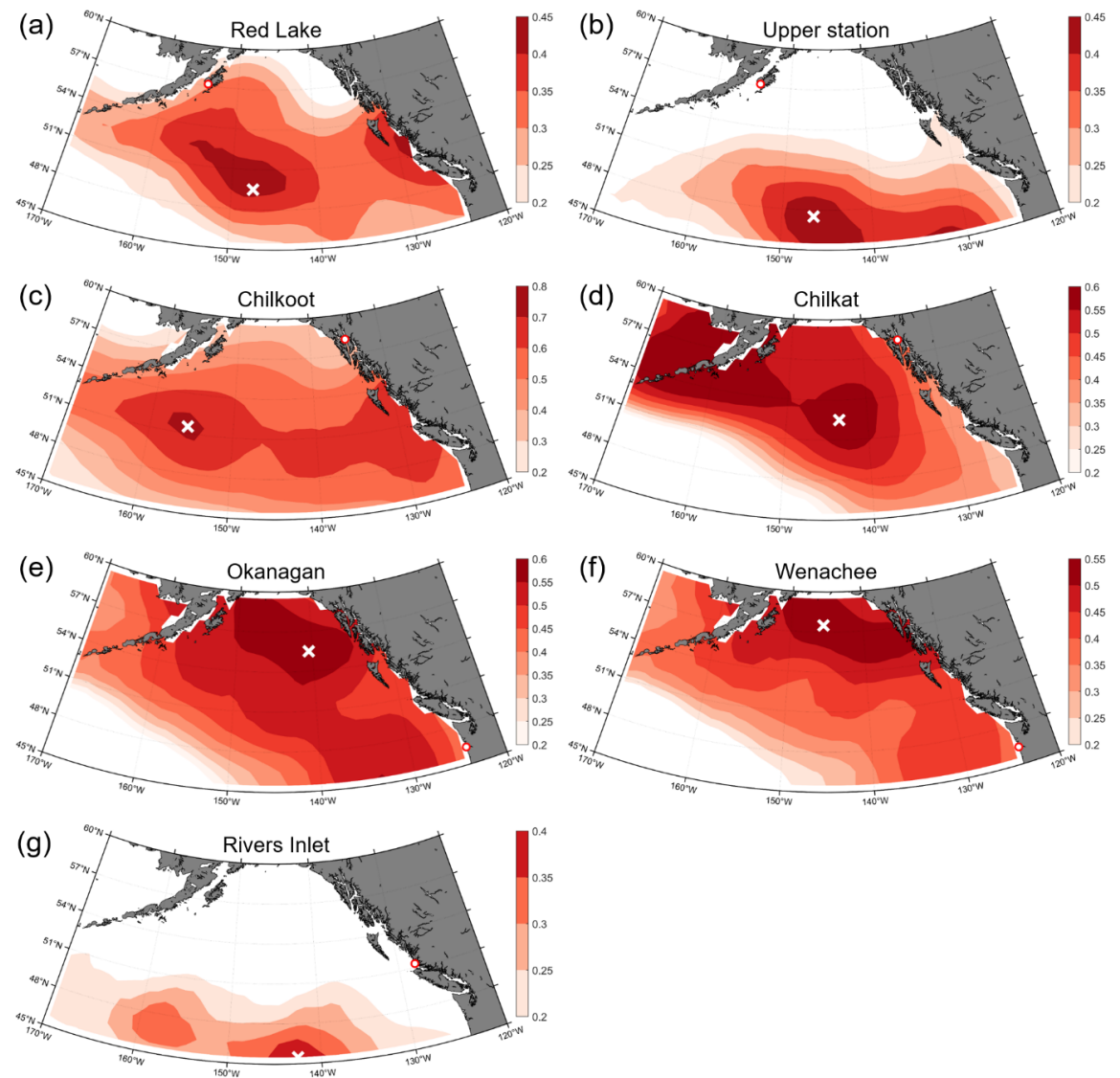

The estimated feeding grounds for stocks with spawning grounds south of the Aleutian Islands were all located in the NE Pacific itself but with little overlap between the stocks (Figure 4). The SE Alaska stocks Chilkat and Chilkoot, which have spawning grounds $10 \mathrm{~km}$ away from each other, showed well separated at-sea locations, with Chilkoot being distributed 10 degrees further west than Chilkat. While Columbia River stocks have the most southerly spawning grounds, their high seas distributions were located in the northern sector of the NE Pacific. The Rivers Inlet stock was distributed further south than any other stock. With the exception of Rivers Inlet, all stocks were sampled yearly and produced significant correlations with highest significance usually found using the original time series (Table 2, correlation coefficients were usually higher with smoothed time series but the adjusted degrees of freedom reduced the

Figure 4. Estimated feeding grounds during the last year at sea of (a) Red lake, (b) Upper station, (c) Chilkoot, (d) Chilkat, (e) Okanagan, (f) Wenachee and (g) Rivers inlet sockeye salmon stocks (Gulf of 
Alaska). Strongest correlation coefficient between $\mathrm{SST}$ and $\delta^{13} \mathrm{C}$ value is indicated by a white cross. Locations of the point of entry in the freshwater system of the different stocks is shown (red circle).

significance, see Methods). Bristol Bay stocks at-sea distributions showed interesting patterns with some stocks being distributed in the Bering Sea and some others along the Aleutian Islands (Figure 5).


Figure 5. Estimated feeding grounds during the last summer at sea of (a) Wood River, (b) Togiak, (c) Nugashak, (d) Igushik, (e) Naknek, (f) Kvichak, (g) Egegik and (h) Ugashik sockeye salmon stocks (Bristol Bay from north to south). Strongest correlation coefficient between SST and $\delta^{13} \mathrm{C}$ value is indicated by a white cross. Locations of the point of entry in the freshwater system of the different stocks is shown (red circle).

Correlation coefficients were relatively less significant for the Bristol Bay stocks, most likely because of the every 3-year sampling resolution that resulted in a low number of data points that did not capture the full extent of interannual variability. No smoothing was applied to the SI values because of the coarse resolution but smoothing the SST series resulted in a slight improvement in the defined areas. Both Russian stocks showed similar at-sea distributions despite originating from opposite side of the Kamchatka Peninsula (Figure 6). Smoothed time series provided more significant correlations for these stocks. 

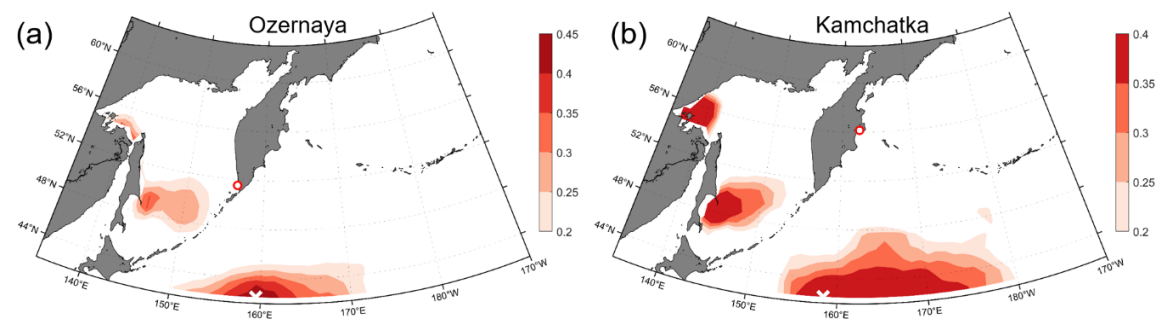

Figure 6. Estimated feeding grounds during the last summer at sea of (a) Ozernaya and (b) Kamchatka sockeye salmon stocks (Russia). Strongest correlation coefficient between SST and $\delta^{13} \mathrm{C}$ value is indicated by a white cross. Locations of the point of entry in the freshwater system of the different stocks is shown (red circle).

The first mode of the EOF analysis applied to SST data for 1968-1998 explained 43\% of the total variance and showed that waters from SW Alaska and North BC coast covaried (Figure 7).



Figure 7. First mode of an EOF analysis using SST averaged each year from January to June for 1968-1998. This mode explained $43 \%$ of the variance.

The feeding grounds of nine of the salmon stocks were located in the NE Pacific. We compared the averaged $\delta^{15} \mathrm{~N}$ values of these stocks with $\delta^{15} \mathrm{~N}$ values extracted from zooplankton isoscapes (Espinasse et al., in press) (Figure 8). The linear regression applied to these data gave an almost 1:1 coefficient with a Y intercept value of 4.6 (with zooplankton as TL=2). Assuming a trophic enrichment factor of 3.43 .30 and 3.76 (Table 3). 


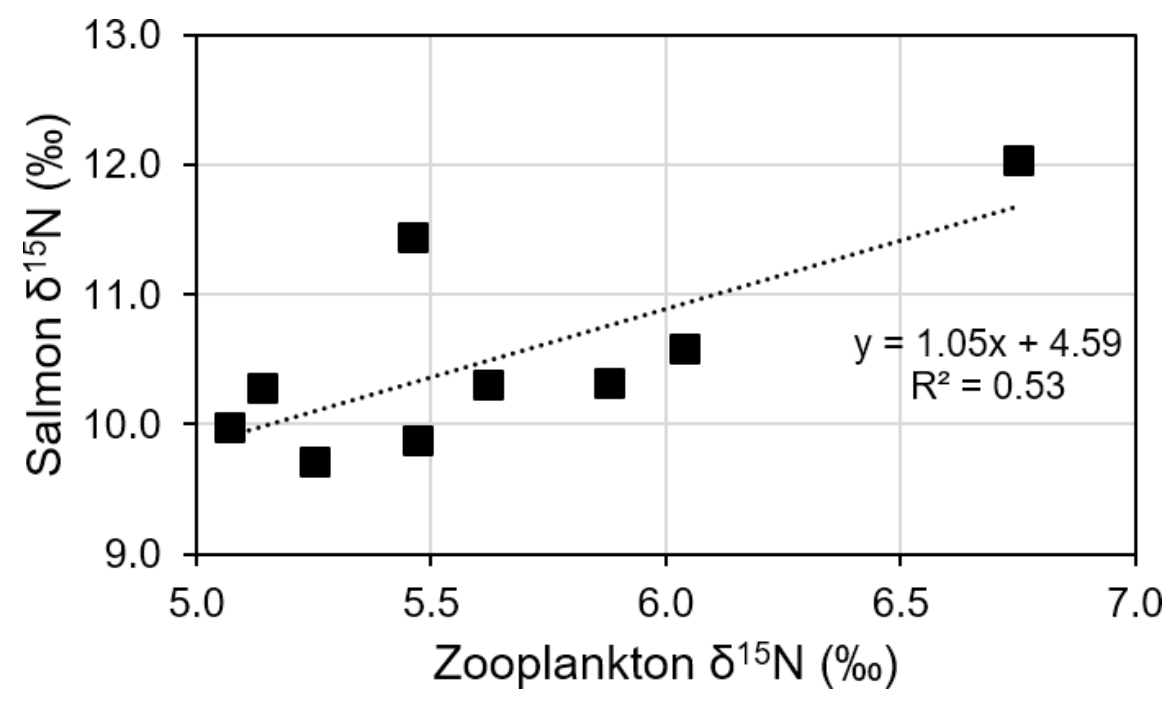

Figure 8. Salmon $\delta^{15} \mathrm{~N}$ plotted against zooplankton $\delta^{15} \mathrm{~N}$ values. Each point represents an average value for a sockeye salmon stock that have been assessed to be distributed in the Gulf of Alaska. Zooplankton $\delta^{15} \mathrm{~N}$ estimates were obtained from isoscapes presented in Espinasse et al., 2019.

Table 3. Trophic level estimates for nine salmon stocks assessed in this study to be distributed in the Gulf of Alaska during their last year at sea. The trophic level is based on the difference between $\delta^{15} \mathrm{~N}$ values in salmon scales and large herbivorous copepods (TL 2) analyzed for this region, assuming a trophic level enrichment factor of 3.4

\begin{tabular}{ll}
\hline Salmon stock & Trophic level \\
\hline Columbia & \\
Okanagan & 3.38 \\
Wenachee & 3.31 \\
Kodiak & \\
Red lake & 3.44 \\
Upper station & 3.30 \\
BC coast & \\
Rivers Inlet & 3.34 \\
Bristol Bay & \\
Naknek & 3.76 \\
Wood River & 3.56 \\
\hline
\end{tabular}

\section{Discussion}

In this study we estimated the high seas distribution and foraging grounds for 17 sockeye salmon stocks, finding significant correlations for 13 of them. However, the spatial pattern of correlation between SST and $\delta^{13} \mathrm{C}$ did not always result in the identification of a single well defined foraging region. Aside from the potential influence of factors other than SST on carbon isotopic composition, the accuracy of the results relies on the assumptions that 1) the fish go to a similar place every year and 2) that they do not move across strong SST/prey $\delta^{13} \mathrm{C}$ gradient during the time period over which the SI values are integrated.

The first assumption is difficult to assess given that there are limited data available on high seas stock-specific locations. The question is probably even more essential for stocks with a strong pattern in age distribution (one predominant age-class), resulting in little mixing between cohorts from different brood years. Another 
aspect that should be investigated is whether there are differences in SI values between early and late runs for the same stock. While for some stocks, adult salmon return predominantly occurs over a short time window, other stocks have two temporally separated runs identified and it is not currently known if high seas distributions differ between runs.

The second assumption is also difficult to evaluate as no data are available for stock-specific movement. A strong gradient in $\delta^{13} \mathrm{C}$ values at lower trophic levels is usually located at the transition between the coastal system (subject to fluvial input, resuspension, etc.) and the open ocean system (more oligotrophic conditions). This transition usually occurs above the shelf or continental slope, depending on the width of the shelf, local hydrodynamics and water depth, but in all cases occurs at a relatively short distance from the coast (El-Sabaawi, Trudel, Mackas, Dower, \& Mazumder, 2012; Kline Jr, 2009). Maturing salmon will likely only swim through this zone once, just before entering the river system and it is therefore unlikely to influence their SI values. They could, however, target areas of higher productivity while in the high seas. For example, eddies have the potential to enhance local primary production that will promote development of salmon prey (Crawford, Brickley, \& Thomas, 2007; Mackas, Tsurumi, Galbraith, \& Yelland, 2005) with higher $\delta^{13} \mathrm{C}$ values (Espinasse et al., in press). Unfortunately, it is not yet documented whether the salmon display such behavior.

\section{Influence of scale sampling method}

Our dataset comprised a mix of SI values measured from whole scales and the last annulus of the scale. We integrated SST over different time ranges to evaluate the best match with the potential integration time of SI values from these different methodologies. The time period from January to June of the return year gave the best results for the two scale sampling methods. This suggested a negligible influence of scale material laid down during the freshwater phase (Hutchinson \& Trueman, 2006) and furthermore that the whole scale SI value was dominated by the last growing season. This can be explained by the largest increase in size and weight of the fish occurring during the last year at sea (Ishida et al., 1998). The mass of collagen produced during this time period largely overwhelms the rest of the scale mass. Our results suggest that using the whole scale did not affect time series comparison, as whole scale and last annulus have very similar SI values (Finney, unpublished data). Studies focusing on the freshwater phase or early marine phase of salmon should however be careful in their interpretations when using scales from maturing fish, as it seems inevitable that the recent layers deposited will strongly influence the SI values (Hutchinson \& Trueman, 2006).

We demonstrated that when analyzing time series of $>20$ data points with yearly resolution, using the original un-treated data gave the most significant results. These data retain the influence of both low and high frequency variations but require correction of the number of degrees of freedom to adjust the p-value (Pyper \& Peterman, 1998). Some stocks with geographically close spawning grounds showed $\delta^{13} \mathrm{C}$ variations driven by different factors. For example, Chilkoot salmon $\delta^{13} \mathrm{C}$ data demonstrated a largely increasing trend from low values in earlier years to high values in later years, while Chilkat did not show a clear long term trend but rather greater interannual variability (Figure S1.2). The Suess effect correction parameter, by changing the overall inclination of the $\delta^{13} \mathrm{C}$ trend, could affect the part of the correlation driven by the low frequency (long term trend). We tested this using data for the Chilkoot and Chilkat stocks and additionally the Okanagan stock for which the data covers more recent years. The Suess effect parameter was set at $-0.015 \mathrm{yr}^{-1}$. This resulted in similar distributions and very little change in correlation significance (Table S1.1). Furthermore, for the large majority of the stocks for which we found significant correlations, the three types of series generated the same distribution. Among the series with yearly resolution, only Red Lake displayed different high correlation areas between the original series and the smoothed series. The detrended series, however gave a similar, but non-significant, distribution to the original one. Overall, using the three approaches enabled improved evaluation of the ocean area most likely used by the salmon, and dismissal of the spots which were only driven by interannual variability or long term trend.

Series with coarser or irregular resolution, usually the smaller datasets $(<20)$, still allowed feeding grounds estimates. Best results were obtained after smoothing the SST series. We tested the effect of sampling resolution by downgrading the resolution of the Okanagan series using data from every $3^{\text {rd }}$ year and obtained 
comparable distributions to the full resolution data set (Figure S1.3). We do not encourage the use of such small datasets, as it is often hard to estimate if the series meets the basic assumptions for correlation test, and there is an increased chance of spurious correlations. Nonetheless, datasets of approximately ten points appear sufficient to provide a meaningful preliminary indication of salmon distribution. We recommend that these are subsequently validated with longer time series.

\section{Feeding grounds definition and validation}

While for some of the stocks, such as Chilkoot, Okanagan and Wenatchee, the method resulted in well-defined feeding ground estimates, estimates for other stocks showed more uncertainty with larger areas showing high correlation and/or multiple regions with high correlation. Several approaches were used to assess these areas and to further resolve the feeding grounds. Data from tagging studies were used to define the limits of where the salmon are likely to be distributed (Figure S1.1). However, these limits encompassed large areas as many stocks were pooled, and so these data were mainly useful to discard high correlation spots that were located outside the potential distribution range. For example, for Red Lake and Upper station stocks (Kodiak Island), two secondary high correlation spots were located eastward of the range determined by the tagging studies and were therefore not considered. The EOF analysis of SST data was useful to understand connectivity between high correlation areas. The Chilkat stock distribution was a good example, with a high correlation area covering a spot in the middle of the Gulf of Alaska and extending northwest to Alaska. This may have been due to the SST of these water masses varying in a similar way during the time period considered for this stock (Figure 7). Based on the tagging study, the central Gulf of Alaska region was estimated to be more realistic.

Another way to validate the inferred stock distributions is to integrate information provided by the $\delta^{15} \mathrm{~N}$ values. We would expect that the stocks with similar foraging areas would also show correlation between their $\delta^{15} \mathrm{~N}$ time series, assuming that they feed at the same trophic level. However, very few stocks showed significant correlation of $\delta^{15} \mathrm{~N}$ values (Figure S1.4). One explanation for this is that there was little overlap between stock distributions. Differences in return timing may also have been a factor, since the $\delta^{15} \mathrm{~N}$ values of prey change rapidly over the productive season. Based on average levels of $\delta^{15} \mathrm{~N}$ and $\delta^{13} \mathrm{C}$ (Figure 3 ), Bristol Bay stocks were separated from the others by their higher SI ratios. This was in agreement with the distributions of the stocks for which the correlation was significant (Ugashik, Naknek and Wood river). These stocks were distributed closer to the coast of the Aleutian Islands or onto the Bering Sea shelf, and both of these areas are more productive and display elevated SI ratios (Pomerleau, Nelson, Hunt, Sastri, \& Williams, 2014). Similarly, we found a correlation between the $\delta^{15} \mathrm{~N}$ of salmon prey and salmon for the stocks with feeding grounds identified in the Gulf of Alaska. This also allowed estimation of the trophic level for these stocks (Table 3). Salmon are reported to feed on a large variety of prey such as copepods, squids, euphausiids and amphipods (Kaeriyama et al., 2004), and, therefore, one would except their trophic level (TL) to range between 3 and 4 , which is consistent with our estimates (TL $=3.3$ to 3.8) and those from Qin and Kaeriyama (2016) (TL $=3.9)$.

\section{Implications}

A broad regional approach, assuming a generalized distribution for all salmon stocks in the North Pacific, has been demonstrated to be useful in linking salmon productivity with climate indices (Malick, Cox, Mueter, Dorner, \& Peterman, 2017; Mantua, Hare, Zhang, Wallace, \& Francis, 1997). However, other studies have stressed the importance of stock specific analysis, as stocks can have different productivity trends despite having geographically close spawning grounds (Quinn, Rich, Gosse, Schtickzelle, \& Grant, 2012; Rogers \& Schindler, 2011), and there is a need to differentiate between factors affecting salmon at local to regional scales (Ohlberger, Scheuerell, \& Schindler, 2016). The unique SI signatures for each stock implies different feeding locations, and this study used a recently developed approach based on SST to infer stock-specific maturing sockeye distributions. Stock-specific at sea distributions is an important knowledge gap that may contribute to understanding of stock specific productivity trends. Changes in environmental conditions due to hydrographic or atmospheric processes impact the physical environment experienced by salmon and the quality and / or quantity of prey that they encounter. Because of the heterogeneity in their prey distribution, 
the high seas distributions of salmon can affect their productivity.

At a large spatial scale, the difference in trends of productivity between Bristol Bay stocks and most of the NE Pacific stocks during the last decades may be explained by differences in high seas distributions. In this study, we found Bristol Bay stocks to be primarily distributed around the Aleutians Island and Bering Sea, while the NE Pacific stocks were distributed in the off shelf area of the Gulf of Alaska. These stocks would thus have experienced different environmental conditions with respect to both annual conditions and long term trends in factors such as SST (Mueter, Peterman, \& Pyper, 2002) and ocean currents (Malick et al., 2017).

At a regional scale, stock-specific distributions can help explain divergence in productivity of stocks with geographically close spawning grounds. Peterman and Brigitte (2012) investigated similarity in temporal variation of productivity of several sockeye stocks and found that among Bristol Bay stocks, Wood River, Naknek, Togiak and Igushik stocks grouped together while Egegik and Ugashik formed another group, breaking the usual south/north geographical separation of the stocks. However, this grouping is consistent with the pattern of salmon at sea distributions found in this study, with Wood River, Naknek and Igushik distributed along the south coast of the Aleutian Islands and Egegik and Ugashik in the Bering Sea. This highlights the uncertainty associated with assuming that stocks with similar spawning ground locations have similar at-sea distributions, and the need for at-sea stock ID data to explicitly connect stocks to high seas conditions.

Another aspect of the high seas life phase that is currently unknown is what drives salmon at-sea distributions. Feeding ground estimates for stocks relative to their origin allows the development of a schematic view of the potential migration sequence determining high-sea salmon distributions. In the NE Pacific, juvenile sockeye salmon enter the ocean at the beginning of summer and typically migrate following the general counter clockwise circulation, northward or westward, depending on stock location, at a speed of about 14 $\mathrm{km} \mathrm{d}^{-1}$ (David W. Welch et al., 2011), although this seems to vary depending on stock (Tucker et al., 2009). The time of ocean entry is influenced by numerous factors, including distance between the rearing lake and the ocean (Carr-Harris et al., 2018) and the seasonal pattern of lake water warming. The timing of ocean entry and the smolt size will define the distance that they are able to cover before their first ocean winter. This, in combination with the entry location, will result in juveniles from different stocks being distributed in different parts of the coast of the Gulf of Alaska when winter starts. We suggest that this will define their high seas distribution for the rest of their marine life assuming that they are then restricted to seasonal offshore/onshore migration in fall/spring (Burgner, 1991). This would explain why Columbia stocks, which have a relatively late ocean entry time due to the long distance from rearing ground to the river mouth, were distributed in the northern part of the Gulf of Alaska. The SE Alaska and Kodiak juvenile salmon seem to move westward and then eventually southward if time allows. For example, Chilkoot smolts, which rear in a glacial lake, likely enter the sea later than Chilkat smolts and were also measured to be significantly smaller in size (Bergander, 1988). As a result, they end up in the area surrounding the Aleutians Islands, while salmon from the nearby clearwater systems such as Chilkat, and Red Lake / Upper station stocks (Kodiak Island) travelled further and were distributed further south. This strategy may allow sockeye salmon to more broadly colonize much of the marine domain, utilizing the ocean carrying capacity over a large area, and minimizing density dependence and risk of food shortage.

\section{Conclusions}

Given potential reductions in favourable habitat due to accelerating global warming, there is an urgent need to better understand the ocean environment experienced by salmon and how this impacts their health and condition. Up to now, little information has been available on stock-specific salmon distribution which hampers our ability to resolve stock-specific dynamics and develop appropriate management plans. The marine environment is heterogeneous, and populations foraging in different areas may be affected in different ways as environmental conditions change. In this study, we showed that salmon stocks with geographically close rearing grounds can have different at-sea distributions, potentially driven by the difference in ocean entry timing and size. Expanding this approach with data from other major sockeye stocks and other salmon 
species would improve understanding of the mechanisms explaining salmon spatial distribution in the high seas, and how this distribution interacts with environmental conditions to affect salmon survival and fitness.

\section{Data availability statement}

All stable isotope data supporting the conclusions of this article is included within the article and supplementary file (Appendix 2).

\section{Competing interests}

The authors declare that they have no competing interests.

\section{Funding}

BE postdoctoral fellowship was founded by The Monell and Vetlesen foundation.

\section{Authors' contributions}

$\mathrm{BE}, \mathrm{BPVH}, \mathrm{BPF}$ and EAP conceived the project. BPF, JKF and AVB provided access to new materials (archived scale) or unpublished salmon stable isotope data. BE carried out the sample and data analysis and wrote the manuscript. All authors provided editorial advice. All authors read and approved the final manuscript.

\section{Acknowledgements}

We thank the Fisheries and Oceans Canada's Schlerochronology Lab at the Pacific Biological Station for providing access to the Rivers Inlet sockeye salmon scale archive, in particular the kind assistance of Darlene Gillespie and Stephen Wischniowski. We thank the Wuikinuxv Nation for ongoing support in sample collection from returning sockeye salmon since 2011, in particular Billie Johnson, Chris McConechy, and David Rolston. We also thank the Columbia River Inter-Tribal Fish Commission for providing access to their archive of sockeye salmon scales; in particular John Whiteaker, Crystal Chulik, and Amber Cate, and all the specialists working at KamchatNIRO who were involved in the sampling and archiving of salmon scales.

\section{References}

Abdul-Aziz, O. I., Mantua, N. J., \& Myers, K. W. (2011). Potential climate change impacts on thermal habitats of Pacific salmon (Oncorhynchus spp.) in the North Pacific Ocean and adjacent seas. Canadian Journal of Fisheries and Aquatic Sciences, 68 (9), 1660-1680. doi:10.1139/f2011-079

Barker, L. J., Hannaford, J., Chiverton, A., \& Svensson, C. (2016). From meteorological to hydrological drought using standardised indicators. Hydrol. Earth Syst. Sci., 20 (6), 2483-2505. doi:10.5194/hess-202483-2016

Bergander, F. (1988). Sockeye salmon stock assessment and evaluation in Southeast Alaska 1983-1984. Retrieved from

Bugaev, A. V., Glebov, I. I., Golub, E. V., Myers, K. W., Seeb, J., \& Foster, M. (2008). Origin and distribution of local sockeye salmon Oncorhynchus nerka stocks in the western part of the Bering Sea in August-October 2006. Russian Journal of Marine Biology, 34 (7), 421-436. doi:10.1134/s1063074008070018

Burgner, R. (1991). Life History of Sockeye Salmon. In C. Groot \& L. Margolis (Eds.), Pacific Salmon Life Histories (pp. 3-117). Vancouver, BC: University of British Columbia Press.

Burkhardt, S., Riebesell, U., \& Zondervan, I. (1999). Effects of growth rate, CO2 concentration, and cell size on the stable carbon isotope fractionation in marine phytoplankton. Geochimica et Cosmochimica Acta, 63 (22), 3729-3741. doi:http://dx.doi.org/10.1016/S0016-7037(99)00217-3

Carr-Harris, C. N., Moore, J. W., Gottesfeld, A. S., Gordon, J. A., Shepert, W. M., Henry, J. D. J., . . . Beacham, T. D. (2018). Phenological Diversity of Salmon Smolt Migration Timing within a Large 
Watershed. Transactions of the American Fisheries Society, 147 (5), 775-790. doi:10.1002/tafs.10068

Chittenden, C. M., Beamish, R. J., \& McKinley, R. S. (2009). A critical review of Pacific salmon marine research relating to climate. ICES Journal of Marine Science, 66 (10), 2195-2204. doi:10.1093/icesjms/fsp174 \%J ICES Journal of Marine Science

Crawford, W. R., Brickley, P. J., \& Thomas, A. C. (2007). Mesoscale eddies dominate surface phytoplankton in northern Gulf of Alaska.Progress in Oceanography, 75 (2), 287-303. doi:http://dx.doi.org/10.1016/j.pocean.2007.08.016

Crossin, G. T., Hinch, S. G., Cooke, S. J., Welch, D. W., Patterson, D. A., Jones, S. R. M., . . . Farrell, A. P. (2008). Exposure to high temperature influences the behaviour, physiology, and survival of sockeye salmon during spawning migration. Canadian Journal of Zoology, 86 (2), 127-140. doi:10.1139/Z07-122

El-Sabaawi, R. W., Trudel, M., Mackas, D. L., Dower, J. F., \& Mazumder, A. (2012). Interannual variability in bottom-up processes in the upstream range of the California Current system: An isotopic approach.Progress in Oceanography, 106 , 16-27. doi:http://dx.doi.org/10.1016/j.pocean.2012.06.004

Espinasse, B., Hunt, B. P. V., Batten Sonia, D., \& Pakhomov, E. A. (in press). Defining isoscapes in the Northeast Pacific as an index of ocean productivity. Global Ecology and Biogeography .

Espinasse, B., Hunt, B. P. V., Doson Coll, Y., \& Pakhomov, E. A. (2018). Investigating high seas foraging conditions for salmon in the North Pacific: insights from a 100 year scale archive for Rivers Inlet sockeye salmon. Canadian Journal of Fisheries and Aquatic Sciences . doi:10.1139/cjfas-2018-0010

French, R., Bilton, H., Osako, M., \& Hartt, A. (1976). Distribution and origin of sockeye salmon (Oncorhynchus nerka) in offshore waters of the North Pacific Ocean. Int. N. Pac. Fish. Comm. Bull., 34

Goericke, R., \& Fry, B. (1994). Variations of marine plankton $813 \mathrm{C}$ with latitude, temperature, and dissolved CO2 in the world ocean. Global Biogeochemical Cycles, 8 (1), 85-90. doi:10.1029/93GB03272

Healey, M. (2011). The cumulative impacts of climate change on Fraser River sockeye salmon (Oncorhynchus nerka) and implications for management. Canadian Journal of Fisheries and Aquatic Sciences, 68 (4), 718737. doi:10.1139/f2011-010

Hirahara, S., Ishii, M., \& Fukuda, Y. (2013). Centennial-Scale Sea Surface Temperature Analysis and Its Uncertainty. Journal of Climate, 27 (1), 57-75. doi:10.1175/JCLI-D-12-00837.1

Hutchinson, J. J., \& Trueman, C. N. (2006). Stable isotope analyses of collagen in fish scales: limitations set by scale architecture.Journal of Fish Biology, 69 (6), 1874-1880. doi:10.1111/j.1095-8649.2006.01234.x

Ishida, Y., Soto-o, I., Ueno, Y., \& Sakai, J. (1998). Seasonal growth patterns of Pacific salmon (Oncorhynchus spp.) in offshore waters of the North Pacific Ocean. N. Pac. Anadr. Fish. Comm. Bull., 1, 66-80.

Johnson, S. P., \& Schindler, D. E. (2012). Four decades of foraging history: stock-specific variation in the carbon and nitrogen stable isotope signatures of Alaskan sockeye salmon. Marine Ecology Progress Series, $460,155-167$.

Kaeriyama, M., Nakamura, M., Edpalina, R., Bower, J. R., Yamaguchi, H., Walker, R. V., \& Myers, K. W. (2004). Change in feeding ecology and trophic dynamics of Pacific salmon (Oncorhynchus spp.) in the central Gulf of Alaska in relation to climate events. Fisheries Oceanography, 13 (3), 197-207. doi:10.1111/j.13652419.2004.00286.x

Kline Jr, T. C. (2009). Characterization of carbon and nitrogen stable isotope gradients in the northern Gulf of Alaska using terminal feed stage copepodite-V Neocalanus cristatus. Deep Sea Research Part II: Topical Studies in Oceanography, 56 (24), 2537-2552. doi:http://dx.doi.org/10.1016/j.dsr2.2009.03.004 
Macdonald, J. S. (2000). Mortality during the migration of Fraser River sockeye salmon (Oncorhynchus nerka): a study of the effect of ocean and river environmental conditions in 1997. Canadian Technical Report of Fisheries and Aquatic Sciences 2315. ( 2315).

Macdonald, J. S., Patterson, D. A., Hague, M. J., \& Guthrie, I. C. (2010). Modeling the Influence of Environmental Factors on Spawning Migration Mortality for Sockeye Salmon Fisheries Management in the Fraser River, British Columbia. Transactions of the American Fisheries Society, 139 (3), 768-782. doi:10.1577/T08223.1

Mackas, D. L., Tsurumi, M., Galbraith, M. D., \& Yelland, D. R. (2005). Zooplankton distribution and dynamics in a North Pacific Eddy of coastal origin: II. Mechanisms of eddy colonization by and retention of offshore species. Deep Sea Research Part II: Topical Studies in Oceanography, 52 (7-8), 1011-1035. doi:http://dx.doi.org/10.1016/j.dsr2.2005.02.008

MacKenzie, K. M., Palmer, M. R., Moore, A., Ibbotson, A. T., Beaumont, W. R. C., Poulter, D. J. S., \& Trueman, C. N. (2011). Locations of marine animals revealed by carbon isotopes. Scientific Reports, 1 , 21. doi:10.1038/srep00021

https://www.nature.com/articles/srep00021\#supplementary-information

MacKenzie, K. M., Trueman, C. N., Palmer, M. R., Moore, A., Ibbotson, A. T., Beaumont, W. R. C., \& Davidson, I. C. (2012). Stable isotopes reveal age-dependent trophic level and spatial segregation during adult marine feeding in populations of salmon. ICES Journal of Marine Science, 69 (9), 1637-1645. doi:10.1093/icesjms/fss074

Magozzi, S., Yool, A., Zanden, H. B. V., Wunder, M. B., \& Trueman, C. N. (2017). Using ocean models to predict spatial and temporal variation in marine carbon isotopes. Ecosphere, 8 (5), e01763. doi:doi:10.1002/ecs2.1763

Malick, M. J., Cox, S. P., Mueter, F. J., Dorner, B., \& Peterman, R. M. (2017). Effects of the North Pacific Current on the productivity of 163 Pacific salmon stocks. Fisheries Oceanography, 26 (3), 268-281. doi:10.1111/fog.12190

Mantua, N. J., Hare, S. R., Zhang, Y., Wallace, J. M., \& Francis, R. C. (1997). A Pacific Interdecadal Climate Oscillation with Impacts on Salmon Production. Bulletin of the American Meteorological Society, 78 (6), 1069-1079. doi:10.1175/1520-0477(1997)078<1069:apicow>2.0.co;2

McKinnell, S., Curchitser, E., Groot, K., Kaeriyama, M., \& Trudel, M. (2014). Oceanic and atmospheric extremes motivate a new hypothesis for variable marine survival of Fraser River sockeye salmon. Fisheries Oceanography, 23 (4), 322-341. doi:10.1111/fog.12063

McKinnell, S. M. (2000). An unusual ocean climate in the Gulf of Alaska during the spring of 1997 and its effect on coastal migration of Fraser River sockeye salmon (Oncorhynchus nerka) . Retrieved from

McMahon, K. W., Hamady, L. L., \& Thorrold, S. R. (2013). A review of ecogeochemistry approaches to estimating movements of marine animals.Limnology and Oceanography, 58 (2), 697-714.

Mueter, F. J., Peterman, R. M., \& Pyper, B. J. (2002). Opposite effects of ocean temperature on survival rates of 120 stocks of Pacific salmon (Oncorhynchus spp.) in northern and southern areas. Canadian Journal of Fisheries and Aquatic Sciences, 59 (3), 456-463. doi:doi:10.1139/f02-020

Ohlberger, J., Scheuerell, M. D., \& Schindler, D. E. (2016). Population coherence and environmental impacts across spatial scales: a case study of Chinook salmon. Ecosphere, 7 (4), e01333-n/a. doi:10.1002/ecs2.1333

Pawlowicz, R. (2019). M_Map: A mapping package for MATLAB (Version 1.4k). Retrieved from www.eoas.ubc.ca/ ${ }^{\sim}$ rich/map.html

Peterman, R. M., \& Brigitte, D. (2012). A widespread decrease in productivity of sockeye salmon (Oncorhynchus nerka) populations in western North America. Canadian Journal of Fisheries and Aquatic 
Sciences, 69 (8), 1255-1260. doi:doi:10.1139/f2012-063

Pomerleau, C., Nelson, R. J., Hunt, B. P. V., Sastri, A. R., \& Williams, W. J. (2014). Spatial patterns in zooplankton communities and stable isotope ratios $(\delta 13 \mathrm{C}$ and $\delta 15 \mathrm{~N})$ in relation to oceanographic conditions in the sub-Arctic Pacific and western Arctic regions during the summer of 2008. Journal of Plankton Research . doi:10.1093/plankt/fbt129

Post, D. M. (2002). Using Stable Isotopes to Estimate Trophic Position: Models, Methods, and Assumptions. Ecology, 83 (3), 703-718. doi:10.2307/3071875

Post, D. M., Layman, C. A., Arrington, D. A., Takimoto, G., Quattrochi, J., \& Montaña, C. G. (2007). Getting to the fat of the matter: models, methods and assumptions for dealing with lipids in stable isotope analyses. Oecologia, 152 (1), 179-189. doi:10.1007/s00442-006-0630-x

Pyper, B. J., \& Peterman, R. M. (1998). Comparison of methods to account for autocorrelation in correlation analyses of fish data. Canadian Journal of Fisheries and Aquatic Sciences, 55 (9), 2127-2140. doi:10.1139/f98104

Qin, Y., \& Kaeriyama, M. (2016). Feeding Habits and Trophic Levels of Pacific Salmon (Oncorhynchus spp.) in the North Pacific Ocean. N. Pac. Anadr. Fish Comm. Bull., 6 , 469-481.

Quinn, T. P., Rich, H. B., Gosse, D., Schtickzelle, N., \& Grant, J. (2012). Population dynamics and asynchrony at fine spatial scales: a case history of sockeye salmon ( Oncorhynchus nerka) population structure in Alaska, USA. Canadian Journal of Fisheries 83 Aquatic Sciences, 69 (2), 297-306. doi:10.1139/f2011-147

Rand, P. S., Hinch, S. G., Morrison, J., Foreman, M. G. G., MacNutt, M. J., Macdonald, J. S., . . . Higgs, D. A. (2006). Effects of River Discharge, Temperature, and Future Climates on Energetics and Mortality of Adult Migrating Fraser River Sockeye Salmon. Transactions of the American Fisheries Society, 135 (3), 655-667. doi:10.1577/T05-023.1

Rau, G. H., Takahashi, T., \& Marais, D. J. D. (1989). Latitudinal variations in plankton 813 C: implications for CO2 and productivity in past oceans. Nature, 341 (6242), 516-518. doi:10.1038/341516a0

Riebesell, U., Burkhardt, S., Dauelsberg, A., \& Kroon, B. (2000). Carbon isotope fractionation by a marine diatom: dependence on the growth-rate-limiting resource. Marine Ecology Progress Series, 193 , 295-303.

Rogers, L. A., \& Schindler, D. E. (2011). Scale and the detection of climatic influences on the productivity of salmon populations. Global Change Biology, 17 (8), 2546-2558. doi:10.1111/j.1365-2486.2011.02415.x

Ruggerone, G. T., \& Connors, B. M. (2015). Productivity and life history of sockeye salmon in relation to competition with pink and sockeye salmon in the North Pacific Ocean. Canadian Journal of Fisheries and Aquatic Sciences, 72 (6), 818-833. doi:10.1139/cjfas-2014-0134

Satterfield, F. R., \& Finney, B. P. (2002). Stable isotope analysis of Pacific salmon: insight into trophic status and oceanographic conditions over the last 30 years. Progress in Oceanography, 53 (2-4), 231-246. doi:http://dx.doi.org/10.1016/S0079-6611(02)00032-0

Sinnatamby, R. N., Bowman, J. E., Dempson, J. B., \& Power, M. (2007). An assessment of de-calcification procedures for $\delta 13 \mathrm{C}$ and $\delta 15 \mathrm{~N}$ analysis of yellow perch, walleye and Atlantic salmon scales. Journal of Fish Biology, 70 (5), 1630-1635. doi:10.1111/j.1095-8649.2007.01434.x

Springer, A. M., \& van Vliet, G. B. (2014). Climate change, pink salmon, and the nexus between bottom-up and top-down forcing in the subarctic Pacific Ocean and Bering Sea. Proceedings of the National Academy of Sciences, 111 (18), E1880-E1888. doi:10.1073/pnas.1319089111

Torniainen, J., Vuorinen, P. J., Jones, R. I., Keinänen, M., Palm, S., Vuori, K. A. M., \& Kiljunen, M. (2014). Migratory connectivity of two Baltic Sea salmon populations: retrospective analysis using stable isotopes of scales. ICES Journal of Marine Science, 71 (2), 336-344. doi:10.1093/icesjms/fst153 
Trueman, C. N., MacKenzie, K. M., \& Palmer, M. R. (2012). Stable isotopes reveal linkages between ocean climate, plankton community dynamics, and survival of two populations of Atlantic salmon (Salmo salar). ICES Journal of Marine Science, 69 (5), 784-794. doi:10.1093/icesjms/fss066

Tucker, S., Trudel, M., Welch, D. W., Candy, J. R., Morris, J. F. T., Thiess, M. E., . . Beacham, T. D. (2009). Seasonal Stock-Specific Migrations of Juvenile Sockeye Salmon along the West Coast of North America: Implications for Growth. Transactions of the American Fisheries Society, 138 (6), 1458-1480. doi:10.1577/T08-211.1

Tzadik, O. E., Curtis, J. S., Granneman, J. E., Kurth, B. N., Pusack, T. J., Wallace, A. A., . . Stallings, C. D. (2017). Chemical archives in fishes beyond otoliths: A review on the use of other body parts as chronological recorders of microchemical constituents for expanding interpretations of environmental, ecological, and lifehistory changes.Limnology and Oceanography: Methods, 15 (3), 238-263. doi:10.1002/lom3.10153

Welch, D. W., Ishida, Y., \& Nagasawa, K. (1998). Thermal limits and ocean migrations of sockeye salmon (Oncorhynchus nerka): long-term consequences of global warming. Canadian Journal of Fisheries and Aquatic Sciences, 55 (4), 937-948. doi:10.1139/f98-023

Welch, D. W., Melnychuk, M. C., Payne, J. C., Rechisky, E. L., Porter, A. D., Jackson, G. D., . . Semmens, J. (2011). In situ measurement of coastal ocean movements and survival of juvenile Pacific salmon.Proceedings of the National Academy of Sciences, 108 (21), 8708-8713. doi:10.1073/pnas.1014044108

Williams, B., Risk, M., Stone, R., Sinclair, D., \& Ghaleb, B. (2007). Oceanographic changes in the North Pacific Ocean over the past century recorded in deep-water gorgonian corals. Marine Ecology Progress Series, $335,85-94$.

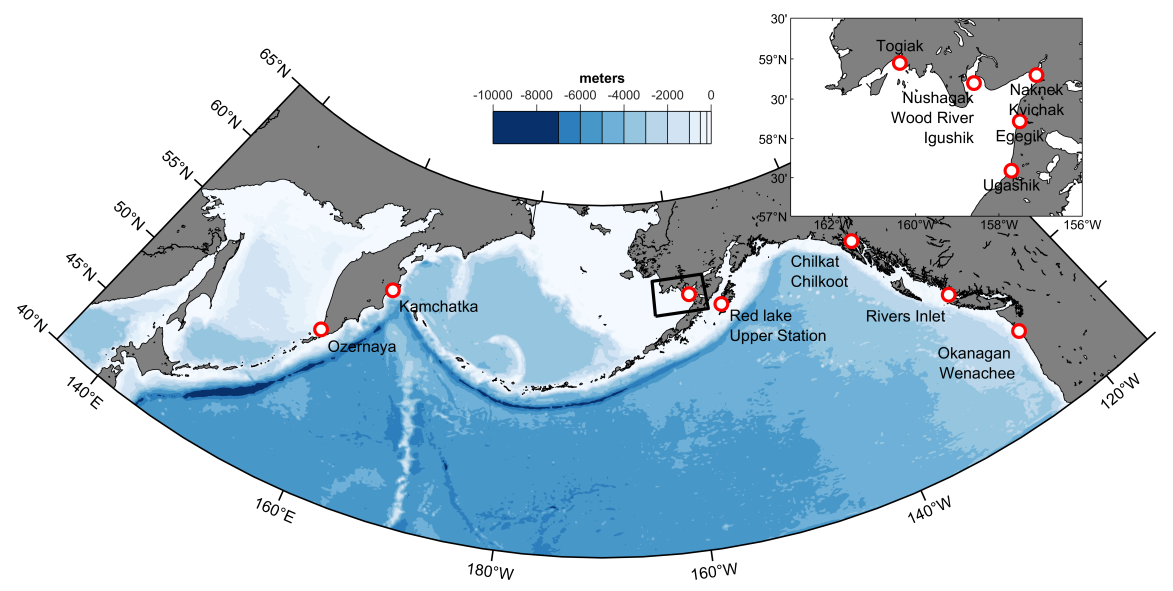



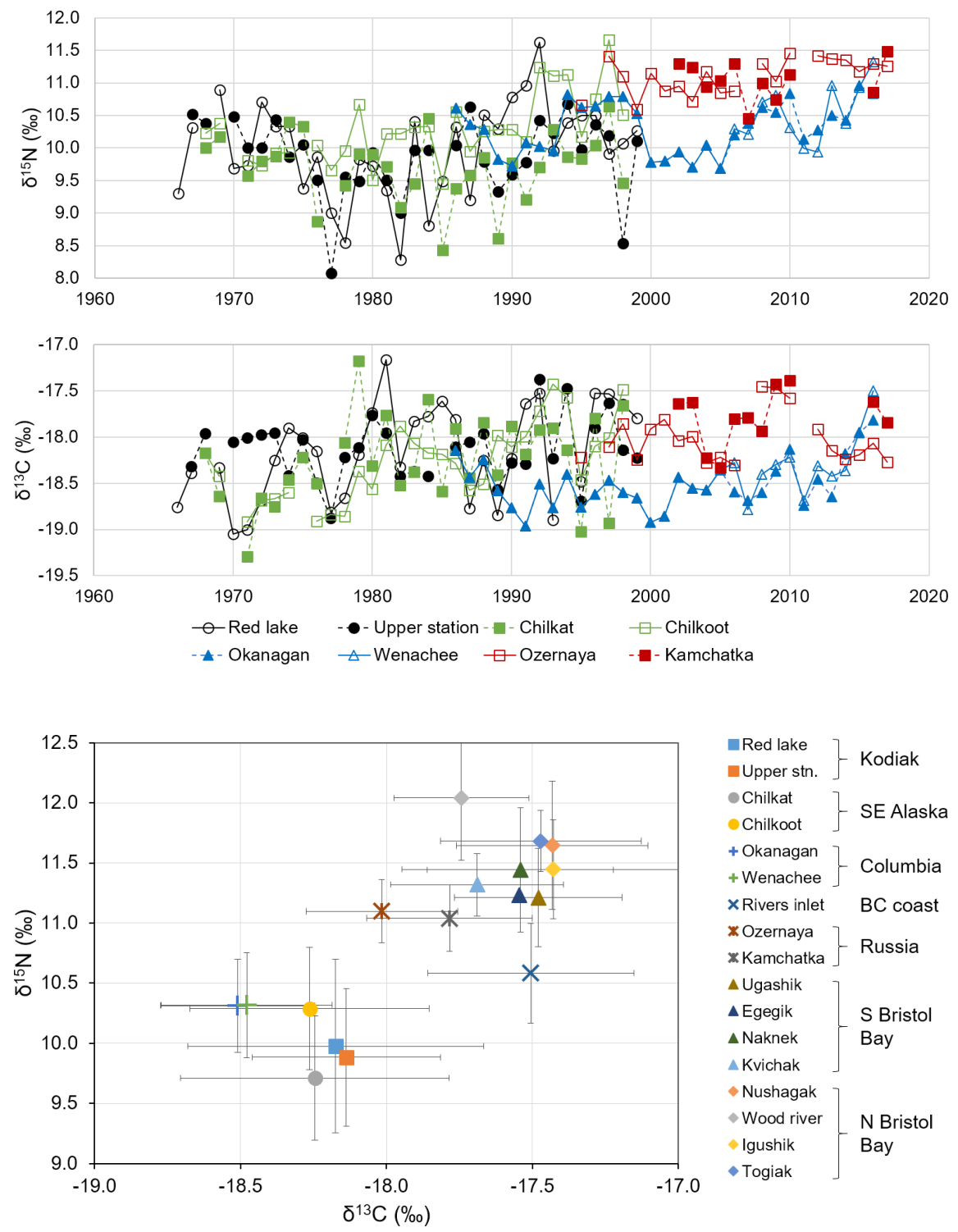

\begin{tabular}{|c|c|}
\hline Red lake & Kodiak \\
\hline Upper stn. & \\
\hline $\begin{array}{l}\text { Chilkat } \\
\text { Chilkoot }\end{array}$ & SE Alaska \\
\hline + Okanagan & \\
\hline + Wenachee & Columbia \\
\hline X Rivers inlet & $\mathrm{BC}$ coast \\
\hline * Ozernaya & \\
\hline ※ Kamchatka & Rus \\
\hline$\Delta$ Ugashik & \\
\hline$\Delta$ Egegik & S Bristol \\
\hline$\Delta$ Naknek & Bay \\
\hline$\triangle$ Kvichak & \\
\hline Nushagak & \\
\hline - Wood river & N Bristol \\
\hline lgushik & Bay \\
\hline - Togiak & \\
\hline
\end{tabular}



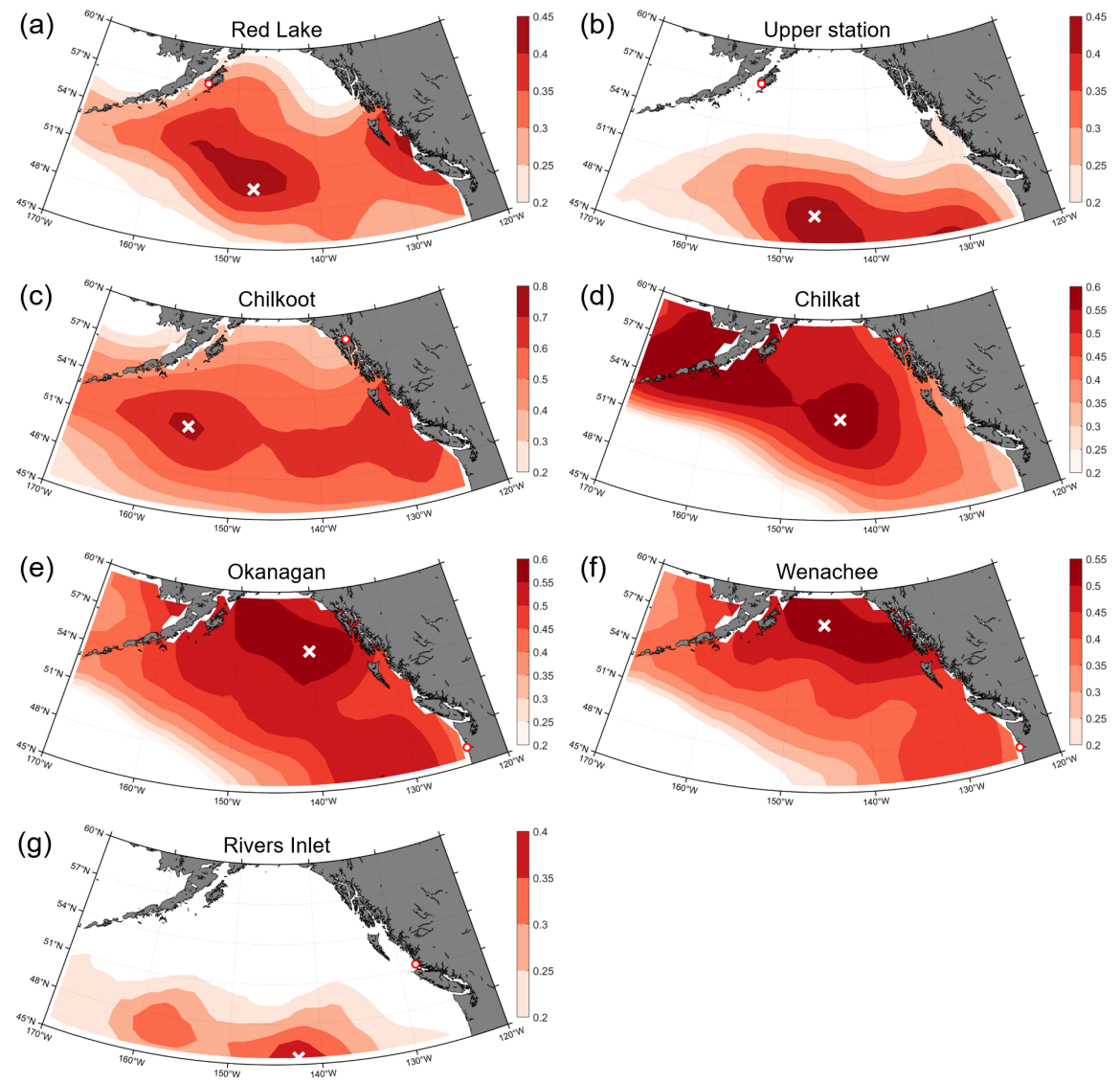

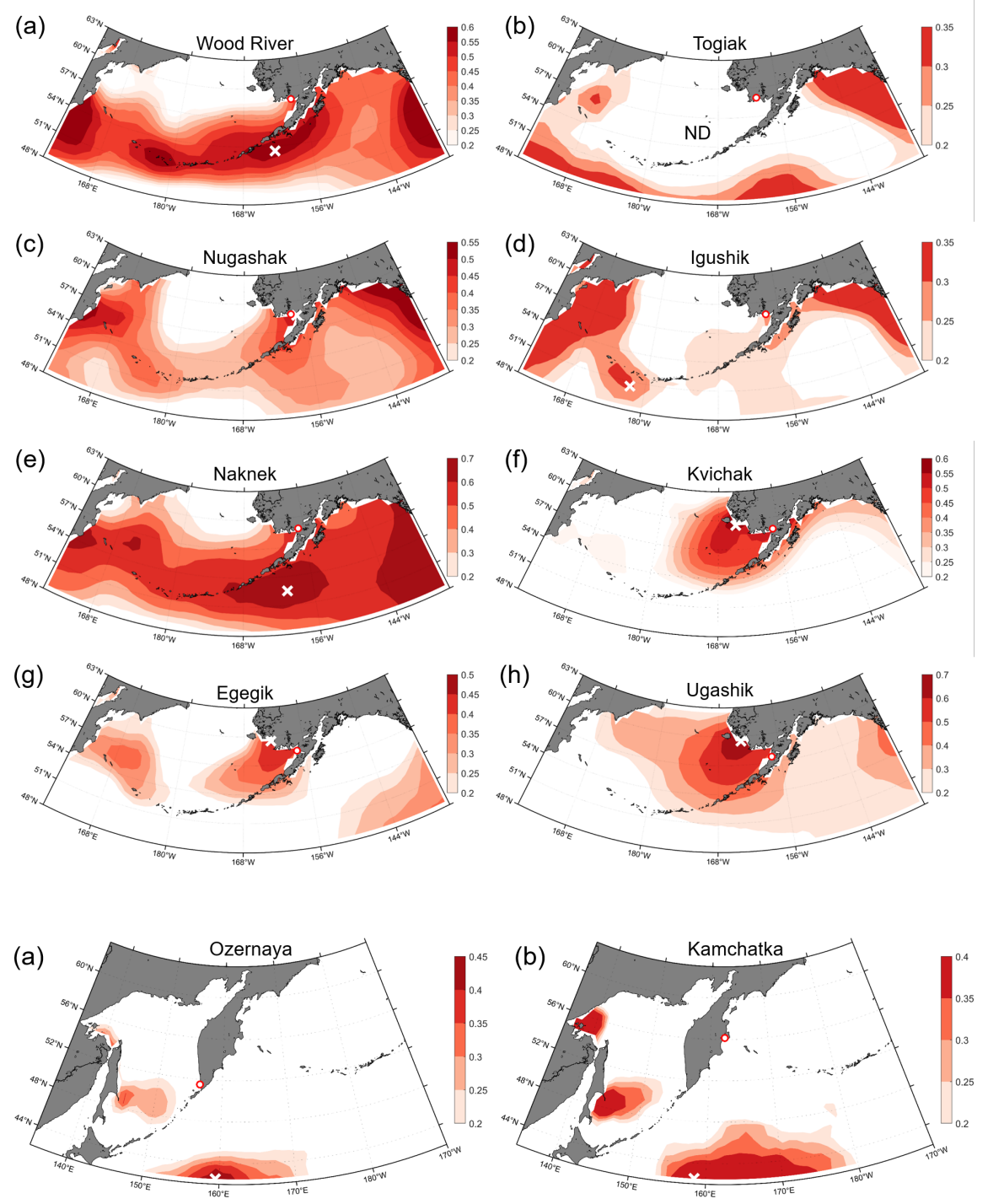

